\title{
Fuel concentration imaging inside an optically accessible diesel engine using I-methylnaphthalene planar laser-induced fluorescence
}

International J of Engine Research 20I4, Vol. I5(6) 74I-750 (c) IMechE 2013

Reprints and permissions: sagepub.co.uk/journalsPermissions.nav DOI: $10.1177 / 1468087413515658$ jer.sagepub.com SAGE

\author{
Johannes Trost', Lars Zigan', Alfred Leipertz', Dipankar Sahoo ${ }^{2}$ and \\ Paul C Miles ${ }^{2}$
}

\begin{abstract}
The performance and emissions of modern automotive diesel engines are highly dependent on the application of pilot injection technology. This technology also appears well suited for application to low-temperature combustion strategies. In this study, the first results of a new quantitative planar laser-induced fluorescence equivalence ratio measurement technique of pilot injections inside an optically accessible diesel engine are presented using I-methylnaphthalene as a tracer in a mixture of the diesel primary reference fuels, n-hexadecane (cetane) and 2,2,4,4,6,8,8-heptamethylnonane (isocetane). This combination overcomes the shortcomings of mismatched fuel volatility and density associated with commonly used toluene/n-heptane/iso-octane planar laser-induced fluorescence techniques. A tracer characterization in a flow cell and a calibration in the internal combustion engine are performed. The internal combustion engine measurements illustrate the mixture formation process for a pilot injection. Even at low injection mass of $3 \mathrm{mg}$, a strong penetration of the pilot is observed; fuel hits the piston bowl wall and is redirected upward to the cylinder head. Small amounts of fuel are also found to have penetrated into the bottom of the piston bowl. At top dead center, the pilot injection is still not completely homogeneously distributed in the piston bowl, and local equivalence ratios of $\Phi>\mathrm{I}$ are found in the bowl.
\end{abstract}

\section{Keywords}

Laser-induced fluorescence, I-methylnaphthalene, pilot injection, EGR, low-temperature combustion

Date received: 18 July 2013; accepted: 31 October 2013

\section{Introduction}

Tracer planar laser-induced fluorescence (PLIF) is a widely used imaging technique for optically accessible internal combustion (IC) engines. ${ }^{1-8}$ It can be applied with high temporal and spatial resolution to image fuel or exhaust gas recirculation (EGR) distributions as well as temperature inside optically accessible IC engines. Commonly applied tracers are acetone, ${ }^{3,7}$ 3-pentanone, ${ }^{9,10}$ toluene (TOL) $)^{7,11-13}$ and triethylamine, ${ }^{8}$ all of which are used for concentration or fuel/air ratio imaging in gasoline engines. A new technique, which employs 1-methylnaphthalene as a tracer in a mixture of the diesel primary reference fuels (PRFs) nhexadecane (nHD) (cetane) and 2,2,4,4,6,8,8-heptamethylnonane (iso-cetane), overcomes the shortcomings of mismatched fuel volatility and density associated with commonly used TOL/n-heptane (nHEP)/iso-octane (ISO) PLIF techniques ${ }^{1-13}$ for measurements in diesel engines. Here, this technique has been applied to investigate the influence of pilot injections on mixture formation in a diesel engine.

The performance and emissions of modern automotive diesel engines are highly dependent on the application of pilot injection technology. Pilot injections, which comprise one or more small injection events that occur prior to the main injection event, are crucial for

\footnotetext{
'Lehrstuhl für Technische Thermodynamik (LTT) and Erlangen Graduate School in Advanced Optical Technologies (SAOT), Friedrich-AlexanderUniversität Erlangen-Nürnberg, Erlangen, Germany

${ }^{2}$ Sandia National Laboratories, Livermore, CA, USA

Corresponding author:

Alfred Leipertz, Lehrstuhl für Technische Thermodynamik (LTT) and Erlangen Graduate School in Advanced Optical Technologies (SAOT), Friedrich-Alexander-Universität Erlangen-Nürnberg, Am Weichselgarten 8, D-91058 Erlangen, Germany.

Email: sek@Itt.uni-erlangen.de
} 
reducing combustion noise levels in automotive diesel engines to acceptable levels. ${ }^{14-16}$ They are also indispensable for reducing low-load hydrocarbon (HC) and carbon monoxide (CO) emissions, ${ }^{14,17}$ particularly under cold-start conditions, which suffer from extended ignition delays and low catalyst temperatures that lead to high $\mathrm{HC}$ and $\mathrm{CO}$ emissions and low oxidation efficiency, respectively. Moreover, a well-optimized pilot injection strategy can significantly improve lowload fuel economy. ${ }^{15,18}$ On the other hand, pilot injections are usually associated with increased soot emissions ${ }^{14-17,19,20}$ and may increase $\mathrm{NO}_{\mathrm{x}}$ emissions unless the pilot injection is quite advanced. ${ }^{14,17}$

Pilot injection strategies also appear well suited for application to low-temperature combustion (LTC) strategies. With LTC, low engine compression ratio and high EGR rates are employed to promote a long ignition delay (increased fuel-charge premixing) and low peak combustion temperatures. These factors result in very low $\mathrm{NO}_{\mathrm{x}}$ and soot emissions, although noise and $\mathrm{HC}$ as well as $\mathrm{CO}$ emissions can be unacceptably high. Employing pilot injection strategies to mitigate these problems would seem to be a natural choice. However, under conditions of small pilot quantity, low temperature or high dilution, the pilot injection ${ }^{21-26}$ can fail to ignite. To overcome this difficulty, increased pilot injection quantities need to be employed..$^{22,27-29}$ Moreover, despite the high EGR rates, a careful matching of pilot-main delay times to swirl level has been found beneficial, ${ }^{30}$ in addition to the well-documented advantages of increased injection pressure in mitigating the increases in soot observed when pilot injections are employed. $^{15,31}$

In this study, first results of a quantitative PLIF equivalence ratio measurement inside an optically accessible diesel engine are presented using 1-methylnaphthalene $(1 \mathrm{MN})$ and the diesel PRFs. Prior to the engine results, a characterization of the tracer in a flow cell is carried out. This technique is a clear step forward in our ability to quantitatively measure in-cylinder fuel/ air ratio distributions in diesel engines, and we anticipate that it will be widely used in the future.

\section{Measurement principle}

Although many different tracers are used in the literature, the basic measurement principle is identical for all PLIF techniques. The signal intensity $S_{f l}$ of the tracer can be calculated by

$$
S_{f l}=\eta \cdot E \cdot \rho_{\text {tracer }} \cdot \sigma(\lambda, T) \cdot \phi\left(\lambda, T, p, \chi_{i}\right)
$$

where $\eta$ is the optical efficiency factor of the setup, $E$ is the laser pulse energy, $\rho_{\text {tracer }}$ is the tracer number density, $\sigma(\lambda, T)$ is the absorption cross section as a function of temperature $T$ and excitation wavelength $\lambda$ and $\phi\left(\lambda, T, p, \chi_{i}\right)$ is the fluorescence quantum yield as a function of temperature $T$, pressure $p$, wavelength $\lambda$ and bath gas composition specified by the mole fractions $\chi_{i}$. The optical efficiency factor can be eliminated by normalizing the signal to a reference signal of known temperature, pressure and bath gas composition and identical optical parameters. The laser pulse energy can be measured with an energy meter, and the excitation wavelength of the laser is known. The pressure can usually be assumed to be a global quantity and, therefore, taken from a pressure transducer.

Depending on the tracer, the bath gas composition can have a significant influence on the signal intensity. The effect of oxygen quenching on aromatic tracers is particularly relevant here. ${ }^{32}$ To minimize this influence, the measurements in this work were conducted in a pure nitrogen atmosphere, so that only nitrogen, surrogate fuel and tracer are present. The surrogate fuel is assumed to have no influence on the signal intensity, so that the bath gas can be treated as pure nitrogen over the whole combustion chamber. This eliminates the influence of $\chi_{i}$, as it does not change either during spray measurements or between reference and spray measurements, leaving only temperature and tracer number density as remaining unknown factors. In this article, the number density of the tracer and consequently of the surrogate fuel are first approximated from the signal intensity assuming that the temperature is uniform throughout the combustion chamber and equal to the pure $\mathrm{N}_{2}$ temperature. With this first approximation of the fuel number density, a new, local temperature is calculated using a simple adiabatic evaporating/cooling model that will be explained in section "Experiment." Afterward, a revised, temperaturecorrected fuel number density is determined using the temperature calibration data presented in section "Temperature calibration."

\section{Tracer selection}

To date, investigations of diesel fuel-air mixing processes have mostly used the typical gasoline tracers TOL in a gasoline surrogate fuel blend of nHEP and ISO. ${ }^{1-13}$ Surrogate fuels based on these gasoline PRFs do not match the physical properties of diesel very well, so the authors suggest using a blend of nHD and heptamethylnonane (HMN) instead. These diesel PRFs have cetane numbers $(\mathrm{CNs})$ of 100 for $\mathrm{nHD}$ and 15 for HMN; hence, every $\mathrm{CN}$ in between can be simulated by an appropriate blend. To guarantee proper coevaporation and thus keep de-mixing effects as low as possible, the physical properties of the tracer should match the surrogate fuel. Relevant properties besides the molar mass, density, viscosity and boiling point are vapor pressure and latent heat of vaporization. Various studies of ISO/3-pentanone mixtures ${ }^{33-36}$ have shown that matching the boiling temperature does not guarantee that the tracer and fuel are co-evaporative. For example, vapor phase concentrations of 3-pentanone above the mixture can change by up to a factor of 2 as vaporization proceeds despite similar boiling 
Table I. Summary of physical properties of different PRFs and tracers.

\begin{tabular}{lllllll}
\hline & $\begin{array}{l}\text { Molar mass } \\
(\mathrm{g} / \mathrm{mol})\end{array}$ & $\begin{array}{l}\text { Density } \\
(\text { at } 298 \mathrm{~K})(\mathrm{kg} / \mathrm{L})\end{array}$ & $\begin{array}{l}\text { Viscosity } \\
(\text { at } 313 \mathrm{~K})\left(\mathrm{mm}^{2} / \mathrm{s}\right)\end{array}$ & $\begin{array}{l}\text { Boiling } \\
\text { point }\left({ }^{\circ} \mathrm{C}\right)\end{array}$ & $\begin{array}{l}\text { Vapor pressure } \\
(\text { at } 313 \mathrm{~K})(\mathrm{kPa})\end{array}$ & $\begin{array}{l}\text { Heat of vaporization } \\
(\text { at } 500 \mathrm{~K})(\mathrm{kJ} / \mathrm{mol})\end{array}$ \\
\hline D2 & - & $0.82-0.85^{\mathrm{a}}$ & $1.9-4.1^{\mathrm{a}}$ & $176-370^{\mathrm{a}}$ & $0.04^{\mathrm{a}}$ & - \\
ISO & $114.2^{\mathrm{b}}$ & $0.69^{\mathrm{b}}$ & $0.66^{\mathrm{c}}$ & $99^{\mathrm{b}}$ & $12.88^{\mathrm{d}}$ & $29.04^{\mathrm{d}}$ \\
$\mathrm{nHEP}$ & $100.2^{\mathrm{b}}$ & $0.66^{\mathrm{b}}$ & $0.51^{\mathrm{b}}$ & $99^{\mathrm{b}}$ & $12.21^{\mathrm{d}}$ & $18.25^{\mathrm{d}}$ \\
nHD & $226.4^{\mathrm{a}}$ & $0.77^{\mathrm{a}}$ & $3.01^{\mathrm{d}}$ & $287^{\mathrm{a}}$ & $0.001^{\mathrm{d}}$ & $59.31^{\mathrm{d}}$ \\
$\mathrm{HMN}$ & $226.4^{\mathrm{a}}$ & $0.79^{\mathrm{a}}$ & $3.20^{\mathrm{d}}$ & $240^{\mathrm{a}}$ & $0.021^{\mathrm{d}}$ & $46.07^{\mathrm{d}}$ \\
TOL & $92.1^{\mathrm{b}}$ & $0.86^{\mathrm{b}}$ & $0.55^{\mathrm{b}}$ & $110^{\mathrm{b}}$ & $7.826^{\mathrm{d}}$ & $24.50^{\mathrm{d}}$ \\
IMN & $142.2^{\mathrm{e}}$ & $1.02^{\mathrm{e}}$ & $5.31^{\mathrm{b}}$ & $244^{\mathrm{e}}$ & $0.030^{\mathrm{d}}$ & $47.65^{\mathrm{d}}$ \\
\hline
\end{tabular}

PRF: primary reference fuel; D2: Diesel 2; nHEP: n-heptane; nHD: n-hexadecane; HMN: heptamethylnonane; TOL: toluene; IMN:

I-methylnaphthalene; ISO: iso-octane.

${ }^{\text {a } D a t a}$ from corresponding material safety data sheet (MSDS).

${ }^{\mathrm{b}}$ Data from FLUIDAT ${ }^{\circledR}$ on the Net. ${ }^{44}$

'Data from Davy et al. ${ }^{45}$

${ }^{\mathrm{D}}$ Data from Daubert and Danner. ${ }^{46}$

eData from Weast. ${ }^{47}$

temperatures. It has to be mentioned that these studies were performed at very different conditions from those expected in a diesel spray. At high temperatures and densities, preferential evaporation is not expected to the same extent in a fine diesel spray, especially since $1 \mathrm{MN}$, nHD and HMN are all nonpolar molecules, whereas 3-pentanone is a polar molecule and ISO and nHEP are nonpolar molecules.

Several studies have previously reported LIF measurements using naphthalenes. ${ }^{37-41}$ Naphthalene $\left(\mathrm{C}_{10} \mathrm{H}_{8}\right)$ was used in laser-induced exciplex fluorescence (LIEF) measurements, ${ }^{38}$ and the mixture formation inside a diesel engine was observed qualitatively with LIF of aromatic compounds that are part of commercial diesel fuel. ${ }^{37}$ Orain et al. ${ }^{40}$ reported a different fluorescence spectrum of $1 \mathrm{MN}\left(\mathrm{C}_{11} \mathrm{H}_{10}\right)$ compared with naphthalene. However, no calibration data and quantitative measurements were performed at IC engine conditions so far. A characterization of several different potential diesel tracers ${ }^{42}$ led to the selection of $1 \mathrm{MN}$ for the present IC engine application. $1 \mathrm{MN}$ was the original diesel PRF with $\mathrm{CN} 0$ before being replaced by HMN and is one of the components in the European Integrated Diesel European Action (IDEA) surrogate fuel. There are kinetic mechanisms developed for it, and accurate data for physical properties are available. Another point in favor of $1 \mathrm{MN}$ is its high thermal stability. Leininger et al. ${ }^{43}$ reported a conversion of only $0.33 \%$ of $1 \mathrm{MN}$ at $10 \mathrm{MPa}$ and $673 \mathrm{~K}$ after $1 \mathrm{~h}$, which leads to the assumption that on a millisecond timescale with pure nitrogen as bath gas in the presented experiments, no relevant pyrolysis occurs during the injection and vaporization of the fuel. Moreover, $1 \mathrm{MN}$ is less hazardous than naphthalene. A summary of the relevant physical properties of gasoline and diesel PRFs and the tracers TOL and $1 \mathrm{MN}$ as well as the standard US diesel fuel Diesel 2 (D2) is given in Table 1.

To characterize $1 \mathrm{MN}$ fluorescence, the temperature and pressure dependence of the fluorescence signal intensity is measured using a high-temperature and high-pressure flow cell designed for tracer calibration. ${ }^{9}$ The tracer is evaporated, mixed with nitrogen and passed through the cell with a mass density of $1 \mathrm{~g} / \mathrm{m}^{3}$. A frequency-quadrupled pulsed Nd:YAG with a wavelength of $266 \mathrm{~nm}$ and a repetition rate of $10 \mathrm{~Hz}$ is used for excitation of the tracer. A light sheet with a thickness of about $500 \mu \mathrm{m}$ in the cell is formed with a cylindrical lens with focal length $500 \mathrm{~mm}$. Perpendicular to the light sheet, an Andor iStar ICCD camera equipped with an UV-Nikkor lens and a WG-280 long-pass filter is used for imaging measurements.

The fluorescence signal intensity is measured at temperatures of 473,673 and $873 \mathrm{~K}$ with pressures of 0.5 , 1,2 and $3 \mathrm{MPa}$. A total of 100 images are recorded at 1 $\mathrm{Hz}$ for every condition and are averaged afterward. An average background image with laser excitation but without tracer in the cell is subtracted from the average image. The laser intensity is measured before and after each condition to keep track of fluctuations and correct them in the post-processing. The average signal value in a region of interest (ROI) of 5670 pixels in the center of every averaged image is calculated, laser fluctuations and concentration differences are accounted for and the signal value is divided by the signal value at $473 \mathrm{~K}$ and $0.5 \mathrm{MPa}$.

Figure 1 shows the normalized signal intensities of $1 \mathrm{MN}$ in nitrogen at all temperatures for 1 and $3 \mathrm{MPa}$. In addition to the measured results, values from the literature ${ }^{40}$ for $1 \mathrm{MN}$ at $0.1 \mathrm{MPa}$ are also given in the figure. The intensity values from the literature are referenced to slightly different conditions. Nevertheless, the temperature dependency of the fluorescence signal intensity of $1 \mathrm{MN}$ matches that seen previously very well. The decrease in the signal intensity with temperature seems to be almost linear with a factor of 10 between 473 and $873 \mathrm{~K}$.

The inhomogeneity of the temperature field in the flow cell was measured with thermocouples at different locations and is estimated to be $3 \%$. Due to the low amount of tracer that is regulated with the mass flow 


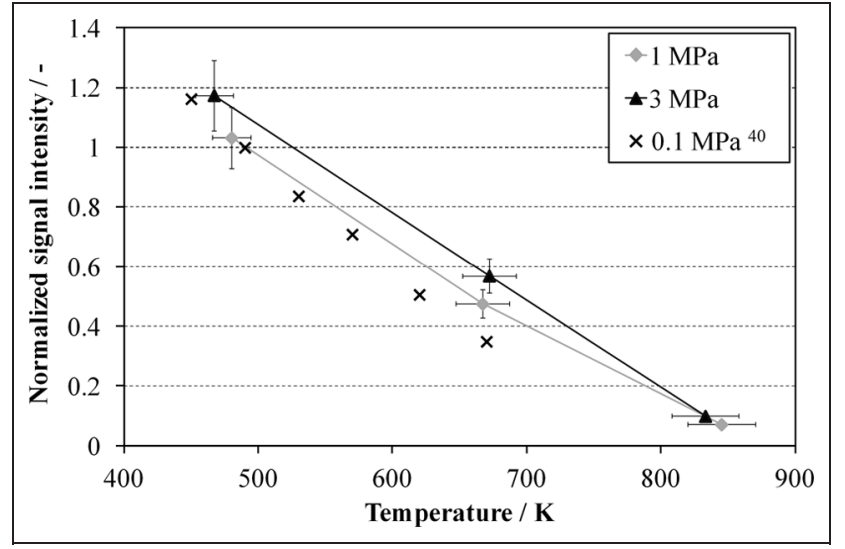

Figure I. Fluorescence signal intensity of IMN with $266 \mathrm{~nm}$ excitation at different temperatures and pressures in the flow cell. Measured data are normalized to $473 \mathrm{~K}$ and $0.5 \mathrm{MPa}$ and literature data ${ }^{40}$ are normalized to $490 \mathrm{~K}$ and $0.1 \mathrm{MPa}$.

Table 2. Engine and fuel injector specifications.

\begin{tabular}{ll}
\hline Engine geometry & \\
Bore & $82.0 \mathrm{~mm}$ \\
Stroke & $90.4 \mathrm{~mm}$ \\
Displacement volume & $0.477 \mathrm{~L}$ \\
Geometric CR & 16.7 \\
Squish height & $0.88 \mathrm{~mm}$ \\
Injection parameters & \\
Injector & Bosch CRI2.2 \\
Sac type & Mini sac \\
Sac volume & $0.23 \mathrm{~mm}^{3}$ \\
Holes & 7 \\
Nozzle diameter & $0.14 \mathrm{~mm}$ \\
Hole geometry & $\mathrm{KSI} .5 / 86$ \\
Included angle & $149^{\circ}$ \\
Rail pressure & $860 \mathrm{bar}$ \\
\hline
\end{tabular}

controller (about $5 \%$ of the maximum value), an overall inaccuracy of the tracer density of up to $10 \%$ is estimated. The estimated errors of temperature and concentration are indicated by the error bars in Figure 1. Compared to the temperature dependency, only a small variation in the signal intensity with nitrogen pressure is observed. Increasing the pressure from 1 to $3 \mathrm{MPa}$ changes the signal intensity by less than $15 \%$. However, even this slight pressure dependency is inconsequential for the IC engine measurements, as flat-field reference images and spray images are recorded at the same pressure conditions.

\section{Engine setup}

The engine used in this study was modified from a 1.9L General Motors light-duty diesel engine to provide extensive optical access to the combustion chamber. The main geometric specifications are provided in Table 2, and a schematic of the engine is shown in Figure 2. The engine features a Bowditch-style piston that has a fused silica piston top with a reentrant bowl and valve cutouts typical of production pistons. Optical access through the sides of the combustion chamber is achieved through fused silica windows ( $50 \mathrm{~mm}$ wide by $25 \mathrm{~mm}$ tall) located at the top of the cylinder liner. These windows are positioned to allow unobstructed optical access up to the bottom surface of the fire deck. The only geometric modifications made to the production design were that the height and width of the top ring land were increased to allow imaging within the bowl portion of the piston. The resulting crevice volume is roughly 3-4 times larger than a production diesel engine. Two gapless compression rings were used to minimize blowby. Despite the larger crevice volume and increased wall temperatures of the fused silica

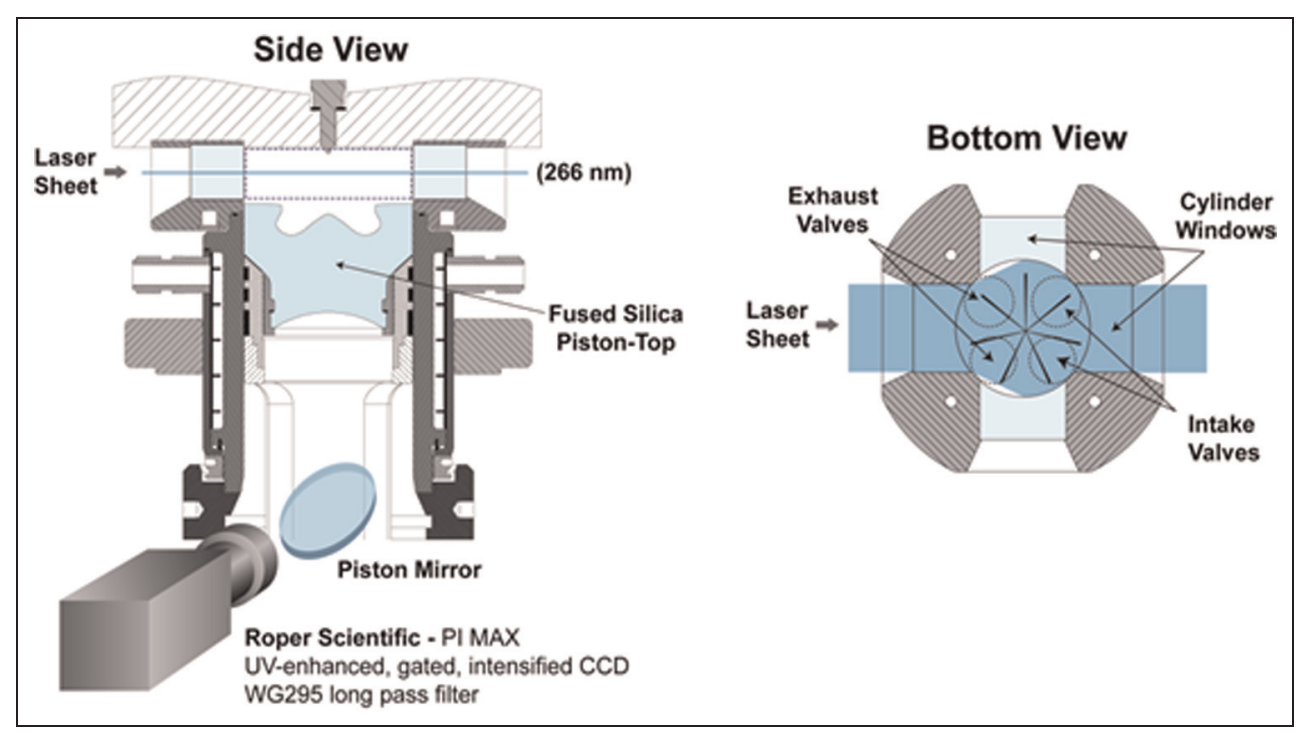

Figure 2. Schematic of the optically accessible diesel engine depicting the location of the laser sheet and camera viewing direction for the horizontal plane measurements. 
surfaces, the optical engine, running in a skip-fired mode, has been shown to reproduce the emissions and combustion behavior of a similar all-metal engine. ${ }^{48}$ The swirl ratio of the in-cylinder flow can also be adjusted via throttle plates located in each of the two intake ports. With both throttle plates in the fully open position, the swirl ratio is 2.2. Throttling the low-swirl, helical port allows the swirl ratio to be increased to 5.5. When the high-swirl, tangential port is throttled, the swirl ratio varies nonmonotonically. A minimum swirl ratio of approximately 1.5 is obtained when the helical port is slightly closed, and the tangential port throttle plate is approximately $30^{\circ}$ from the closed position. ${ }^{49}$ The optical engine is also equipped with a Kistler $6125 \mathrm{~B}$ pressure transducer, and the in-cylinder pressure is acquired every $0.25^{\circ}$ crank angle (CA).

The fuel injector used in this study is a Bosch CRI2.2 high-pressure, electronically controlled, common-rail injector. The injector is equipped with a seven-hole, mini-sac injector tip with an included angle of $149^{\circ}$. The seven fuel orifices are equally spaced and have a nominal diameter of $0.14 \mathrm{~mm}$. Additional specifications for the fuel injector are included in Table 2.

\section{Experiment}

Tracer PLIF using $1 \mathrm{MN}$ is applied to image pilot injection fuel concentration in a diesel engine. As modern diesel engines have a lower compression ratio and operate at higher EGR rates, larger pilot injections are used, and the data obtained are useful for understanding the pilot injection mixture preparation and ignition processes. To prevent ignition of the fuel as well as the strong influence of oxygen quenching on the fluorescence signal intensity, the experiments are conducted in a pure nitrogen atmosphere. The local equivalence ratio $\Phi$ is calculated from the measured fuel concentration and the assumption that the intake charge contains $14 \%$ oxygen, which is typical of a high-EGR, light-load operating condition. Due to different heat capacities of the species in the combustion chamber, the inlet temperature and pressure have to be adjusted for measurements with pure nitrogen to obtain the same peak temperature and density at top dead center (TDC) as for a real gas mixture including water vapor and carbon dioxide. A GT-Power simulation is used to calculate the inlet temperature of $381 \mathrm{~K}$ and inlet pressure of $0.15 \mathrm{MPa}$ needed to achieve an average temperature and density between $15^{\circ} \mathrm{CA}$ before top dead center (bTDC) and TDC of $930 \mathrm{~K}$ and $19.6 \mathrm{~kg} / \mathrm{m}^{3}$, respectively. As no combustion takes place, the measured $\Phi$ can only be transferred to fire conditions as long as no significant heat release has yet occurred. The IC engine is operated under skip fire conditions, so that only every fifth cycle an injection takes place. The engine is operated at $1500 \mathrm{~min}^{-1}$ with a swirl ratio of 4.5 . The start of injection is at $15^{\circ} \mathrm{CA}$ bTDC. The injection duration is $340 \mu \mathrm{s}$, which corresponds to an injected pilot mass of $3 \mathrm{mg}$. A subsequent main injection is not performed in this experiment.

A mixture of $42 \%$ of nHD and $58 \%$ of $\mathrm{HMN}$ by volume is used as fluorescence-free surrogate fuel. This mixture was determined in previous experiments to match the ignition behavior and heat release of a reference Chevron Diesel 2 fuel with a CN of 47 exactly. The base fuels nHD and HMN are available in a purity of $99 \%$ and $98 \%$, respectively. Preliminary spray measurements are conducted to estimate fluorescence from impurities of the surrogate fuel mixture. The signal is below the detection limit of the experimental setup as only noise remains after background subtraction. The tracer $1 \mathrm{MN}$ is added to the fuel mixture in an amount of $0.5 \%$ by volume. As already explained in section "Tracer selection," the physical properties of this mixture match the properties of Diesel 2 much better than the properties of typically used mixtures based on the gasoline PRFs (nHEP/ISO/TOL).

For excitation of the fluorescence, a frequencyquadrupled Nd:YAG with $266 \mathrm{~nm}$ wavelength and a repetition rate of $10 \mathrm{~Hz}$ is used. The average pulse energy is adjusted to about $30 \mathrm{~mJ}$ using a polarization beam splitter and a $\lambda / 2$ wavelength plate. This pulse energy is low enough to not damage the optical engine and equipment and still yield high signal intensity. The laser energy is monitored and recorded for each image with a coherent model J-25MB-LE energy sensor. The horizontal light sheet has a thickness of about $0.5 \mathrm{~mm}$ in the measurement area. It is coupled into the combustion chamber from the exhaust side and leaves the engine through an intake side window to reduce interference from reflections of the laser. Three different planes inside the cylinder are investigated, as shown in Figure 3. Plane P1 bisects the clearance volume between piston and cylinder head, P2 is a few millimeter below the piston surface in the piston bowl and P3 is deep within the piston bowl, at the maximum bowl diameter. For all three planes, measurements are carried out between $12^{\circ} \mathrm{CA}$ and $0^{\circ} \mathrm{CA}$ bTDC in steps of $2^{\circ} \mathrm{CA}$. The light sheet is aligned for each crank angle degrees to keep the same position in the piston bowl or between piston and cylinder head. The exact distance of the light sheet to the cylinder head for all measurements is given in Table 3.

A Roper Scientific PI-Max ICCD camera equipped with a $105-\mathrm{mm}$ focal length $\mathrm{f} / 4.5 \mathrm{UV}-\mathrm{Nikk}$ or lens is used for imaging. The intensifier gate is kept constant at $250 \mathrm{~ns}$, and the camera gain is fixed for all

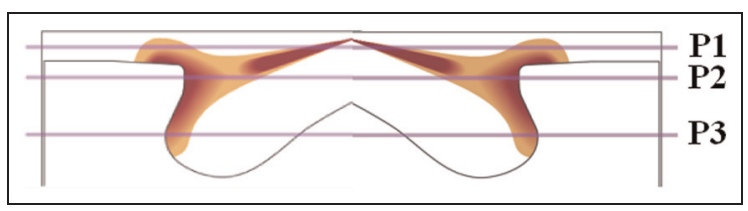

Figure 3. Position of the three investigated planes PI, P2 and P3. 
Table 3. Distance between light sheet and cylinder head in millimeter for all planes and CAs.

\begin{tabular}{llll}
\hline${ }^{\circ} \mathrm{CA}$ bTDC & $\mathrm{PI}$ & $\mathrm{P} 2$ & $\mathrm{P} 3$ \\
\hline 12 & 1.1 & 4.8 & 11.8 \\
10 & 0.9 & 4.5 & 11.5 \\
8 & 0.8 & 4.2 & 11.2 \\
6 & 0.7 & 3.9 & 10.9 \\
4 & 0.6 & 3.8 & 10.8 \\
2 & 0.5 & 3.7 & 10.7 \\
0 & 0.5 & 3.7 & 10.7 \\
\hline
\end{tabular}

CA: crank angle; bTDC: before top dead center.

measurements. A WG-295 long-pass filter is used to block elastically scattered laser light. As the fluorescence spectrum of naphthalenes is at wavelengths of $300 \mathrm{~nm}$ and higher, ${ }^{40,42}$ no difference in the signal intensities is expected using a WG-295 or a WG-280 filter as was used for the tracer calibration. The laser and camera are synchronized with the engine and externally triggered.

To guarantee consistent thermal boundary conditions for all measurements, the experiments are conducted following a tight schedule. After three warm-up runs, constant conditions are achieved. The engine is started every $8 \mathrm{~min} 30 \mathrm{~s}$ and stopped after $3 \mathrm{~min} 30 \mathrm{~s}$ to guarantee a break of $5 \mathrm{~min}$ to protect the optical elements of the engine from overload. Within this break, the acquisition for the following measurement can be set and the light sheet can be adjusted. Due to the dropdown liner design of the engine, this break can also be used to open the cylinder, clean the piston and windows and close the cylinder again. During each run, 50 background, flat-field and spray images are acquired. The background is taken with the laser firing but without fuel injection. For the flat-field images, nine short injections are conducted during the intake stroke to achieve a homogeneous mixture with $\Phi=0.28$ during compression. The injections during the intake stroke were investigated with a high-speed camera in preliminary experiments to exclude wetting of the cylinder wall with liquid fuel, which could lead to a fuel loss and consequently to a lower flat-field concentration.

For post-processing, the spray and flat-field images are first corrected by normalizing by the laser power and subtracting the averaged, normalized background image. Afterward, a distortion correction is applied because the curved piston geometry heavily distorts the images. The processed images are averaged and the spray image is divided by the flat-field image. With this ratio, an initial estimate of the fuel concentration can be determined assuming a homogeneous temperature in the cylinder that is calculated using a GT-Power simulation. The adiabatic mixing temperature is achieved when liquid fuel at $363 \mathrm{~K}$ is vaporized and mixed with the ambient charge and is estimated with a simple model using the fuel enthalpy of evaporation, the measured concentration and the temperature-dependent gas-phase enthalpies of the fuel and the $\mathrm{N}_{2}$ charge gas.
Afterward, the concentration is calculated again from the ratio of spray and flat field using the corrected temperature field obtained after the application of the mixing model and a calibration function. This function is obtained from in-cylinder tracer calibration measurements and is explained in the subsequent chapter. Finally, the equivalence ratio $\Phi$ is calculated assuming $14 \%$ oxygen in the charge. Stoichiometric combustion of 1 mole $\mathrm{C}_{16} \mathrm{H}_{34}$ requires 24.5 moles of oxygen and consequently 175 moles of charge when the $\mathrm{O}_{2}$ mole fraction is 0.14 . The equivalence ratio can then be related to the mole fraction of the fuel $\chi_{\text {fuel }}$ through

$$
\Phi=\frac{\chi_{\text {fuel }}}{\left(1-\chi_{\text {fuel }}\right)} \cdot 175
$$

Two principal sources of systematic interference in the measurement remain even after the background subtraction. Reflections of the LIF signal from surfaces of the combustion chamber can lead to an overestimation of $\Phi$ in lean regions, especially when strong fluorescence from liquid fuel is present. This effect is most severe when regions with very low and very high equivalence ratio coexist within the plane of the laser sheet and when the sheet is positioned close to the cylinder head (e.g. in P1). The other interference is also associated with strong fluorescence from liquid fuel and is caused by reflections of the laser on combustion chamber surfaces. These reflections can excite sufficient fluorescence from liquid fuel near the injector that is observed in the PLIF images from the lower planes. The interferences lead to an overestimation of $\Phi$ and are typically confined to a relatively small region near the center of the cylinder.

An additional potential error induced by the inability to resolve a pressure dependency of the fluorescence signal potentially impacts the temperature calibration and is assumed to be within the standard deviation of the calibration. Since the pressure is almost identical for the spray and flat-field images and the ratio of these images is used for the post-processing, this pressure dependency does not impact the data directly. Likewise, uncertainties in our charge gas temperature estimates, particularly in P1 where boundary layer effects may be significant, will be similar in both the data and the flatfield images, and the errors induced largely selfcanceling.

\section{Temperature calibration}

The characterization of $1 \mathrm{MN}$ in a flow cell shows a significant dependency of the fluorescence signal intensity on temperature. To obtain a correction function for the post-processing of the IC engine measurement, an incylinder temperature calibration is carried out prior to the pilot injection study. For this calibration, the engine is operated with the same fuel injection strategy as for the flat-field images described in the previous chapter. A homogeneous mixture near TDC is achieved by nine 


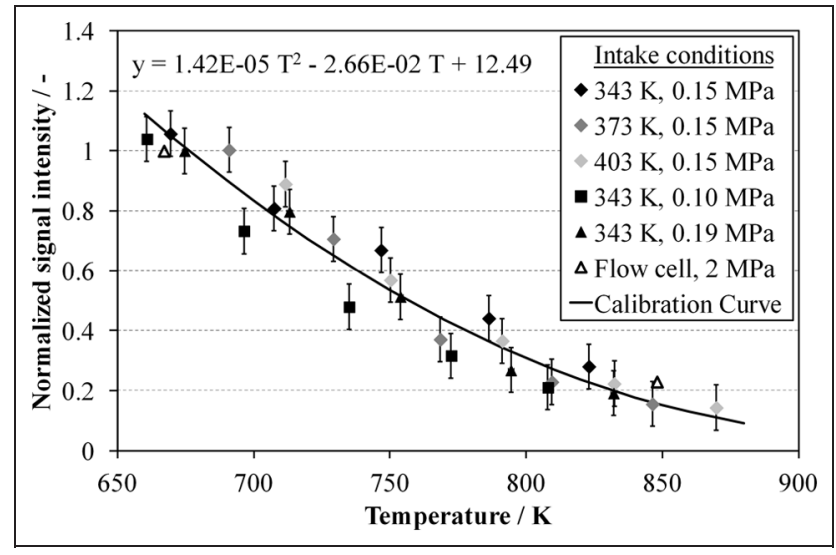

Figure 4. Results of the in-cylinder calibration for different intake conditions. The error bars indicate I $-\sigma$ standard deviation. The resulting calibration curve and its function as well as exemplary results from the flow cell are also shown.

short injections in the intake stroke. For each calibration point, 50 images are recorded and averaged. The average in-cylinder temperature depending on $\mathrm{CA}$ is calculated using a GT-Power simulation. This temperature is used as calibration value for the averaged fluorescence intensity in a homogeneous ROI close to the center of the averaged image. The light sheet position is fixed for the calibration measurement at a distance of $1.1 \mathrm{~mm}$ from the cylinder head. To vary temperature and pressure, three different intake temperatures 343, 373 and $403 \mathrm{~K}$ as well as three different intake pressures $0.1,0.15$ and $0.19 \mathrm{MPa}$ are used for the calibration. For each condition, measurements are carried out between $35^{\circ} \mathrm{CA}$ bTDC and $15^{\circ} \mathrm{CA}$ bTDC in steps of $5^{\circ} \mathrm{CA}$. Figure 4 shows the results of the temperature calibration, normalized to the intensity at $35^{\circ} \mathrm{CA}$ bTDC for $343 \mathrm{~K}$ and $0.19 \mathrm{MPa}$ intake temperature and pressure, respectively. The actual conditions for this reference point are $673 \mathrm{~K}$ and $2 \mathrm{MPa}$. Additionally, the results from the flow cell measurement at $2 \mathrm{MPa}$ normalized to $673 \mathrm{~K}$ are shown. Although only two points are within the investigated temperature range for the IC engine measurement, it can be seen that the decrease in signal intensity is very similar to the in-cylinder calibration. No distinct pressure dependency is seen. The interpolated function

$$
y=1.42 E-05 \cdot T^{2}-2.66 E-02 \cdot T+12.49
$$

only depends on temperature and is used for temperature correction in the post-processing; its curve is also shown in Figure 4. The error bars indicate the $1-\sigma$ standard deviation of the measured values to the calibration curve, which is 0.075 . The quadratic fit describes the calibration data well; the coefficient of determination $R^{2}$ is 0.943 .

\section{IC engine results}

Due to the piston geometry, the field of view is different for all three investigated planes, as distortion and

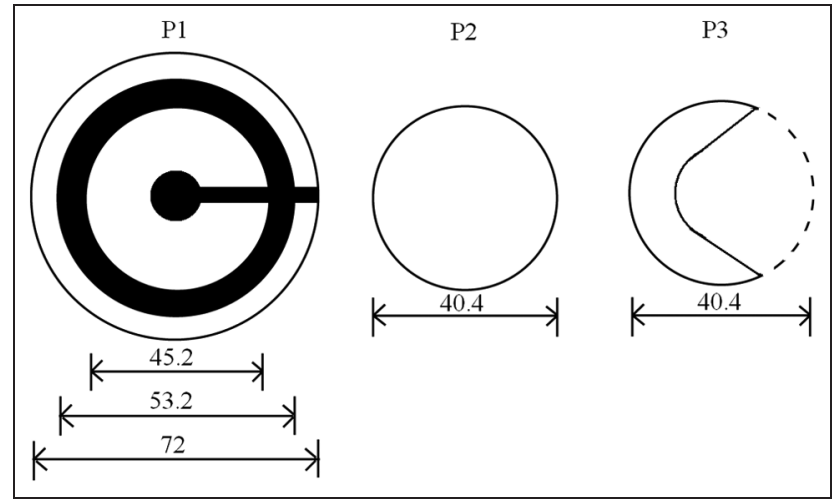

Figure 5. Evaluable areas of all three investigated planes. Masked regions are shown in black and are not included in the results.

reflections close to surfaces result in interferences with the signal. Figure 5 shows the regions of each plane within which the data can be evaluated quantitatively. As plane $\mathrm{P} 1$ is above the piston, a ring outside the piston bowl up to a 5-mm distance from the cylinder wall as well as the area above the piston bowl can be evaluated. Above the reentrant portion of the bowl, the refraction is too strong to process any data even after the distortion correction, so that the results between radii of 22.6 and $26.6 \mathrm{~mm}$ are masked. Additionally, the laser hits the injector tip causing interferences from reflections close to the tip and a dark area in the shadow of the tip, where the signal-to-noise ratio (SNR) is too low to process the image. Both regions are masked in the results. Plane P2 is in the upper part of the piston bowl, and measurements are available up to a radius of $20.2 \mathrm{~mm}$, which is $2.4 \mathrm{~mm}$ from the piston bowl rim. The same outer radius applies for Plane P3, which is additionally restricted by the inner bowl pip and the shadow created behind it. Results are available within approximately $4.9 \mathrm{~mm}$ of the bowl periphery and $1.9 \mathrm{~mm}$ of the inner bowl pip.

Figure 6 shows the equivalence ratio results for all planes and CAs. Especially shortly after the end of injection, the intensity between the single spray cones is different. This can be explained in large part by different zenith angles of the spray cone centerlines and is not an effect of different injected masses from the individual injector holes. Spray cones with more fuel in P1 in general show less fuel in lower planes, which are also further away from the injector tip. This can be seen clearly for the lower left ( $\sim 7 \mathrm{o}$ ' clock) cone from $12^{\circ} \mathrm{CA}$ to $8^{\circ} \mathrm{CA}$ bTDC. Compared to the other spray cones, this cone shows the highest intensity in P1 and the lowest intensity - at the largest radial locations - in $\mathrm{P} 2$, which are signs of a flatter injection angle. The fuel jet hits the piston bowl wall already at $12^{\circ} \mathrm{CA}$ bTDC as seen in $\mathrm{P} 2$, indicating a strong penetration of the spray despite the low injected mass of $3 \mathrm{mg}$. At $10^{\circ} \mathrm{CA}$ bTDC, the bottom-right (4 and 6 o' clock) cones show a redirection of the fuel from the piston bowl upward 


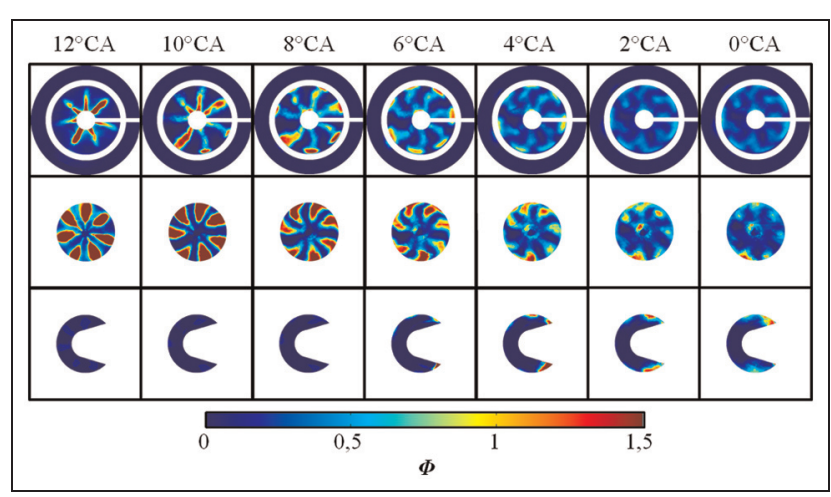

Figure 6. Equivalence ratio results from $12^{\circ} \mathrm{CA}$ to $0^{\circ} \mathrm{CA}$ bTDC for planes PI (top row), P2 (middle row) and P3 (bottom row).

into $\mathrm{P} 1$, which can be seen for all seven cones at $6^{\circ} \mathrm{CA}$ bTDC. Nevertheless, only a small amount of fuel penetrates into the squish volume above the piston and outside of the bowl, which can be seen in the outer ring of P1. The upward movement of the piston pushes the charge out of the squish volume, ${ }^{50}$ which prevents the fuel from further penetrating into the squish volume and pushes it back toward the injector tip, improving the mixing in $\mathrm{P} 1$ from $6^{\circ} \mathrm{CA}$ to $0^{\circ} \mathrm{CA}$ bTDC. Penetration of fuel into $\mathrm{P} 3$ occurs at $6^{\circ} \mathrm{CA}$ bTDC. At TDC, when the main injection starts, the pilot injection is still not completely homogeneously distributed in the piston bowl and local equivalence ratio regions with $\Phi$ $>1$ are found in $\mathrm{P} 2$.

Due to the swirl, the charge rotates in a clockwise direction, moving the fuel-rich regions away from the original azimuthal orientations of the jet centerlines. Thus, the injection timing of the pilot and main injection has to be adjusted to the swirl ratio to position the rich regions of the pilot, where ignition and high temperature or radical concentrations are expected, close to the spray cone of the main injection. Close to TDC, a strong signal close to the injector tip can also be seen in P2, which indicates the presence of liquid droplets. Obviously, these droplets do not penetrate far into the combustion chamber, which means they are probably produced during the closing of the injector and remain close to the injector tip as they have only a small momentum.

\section{Conclusion}

A new PLIF equivalence ratio measurement technique using $1 \mathrm{MN}$ as a tracer for a fuel mixture of the diesel PRFs nHD and HMN is used to investigate quantitatively the vaporization and mixing behavior of pilot injections in an optically accessible diesel engine at LTC conditions. The new fuel/tracer system provides a closer match to the physical properties of commercial diesel fuel than the more commonly used nHEP/ISO/TOL mixtures. A characterization of $1 \mathrm{MN}$ in a flow cell led to the selection of this tracer for IC engine application.
Temperature calibration of the tracer was carried out in the engine prior to the pilot injection study and closely matched the results obtained in the flow cell.

The IC engine measurements illustrate the mixture formation process for a pilot injection, prior to the main injection. Even at low injection mass of $3 \mathrm{mg}$, a strong penetration of the pilot is observed; fuel hits the piston bowl wall and is redirected upward to the cylinder head. Fuel only slightly penetrates into the squish volume and is pushed out again by the upward movement of the piston, improving the mixing near the bowl rim close to the cylinder head. Small amounts of fuel are also found to have penetrated into the bottom of the piston bowl. At TDC, when a main injection would start, the pilot injection is still not completely homogeneously distributed in the piston bowl and local equivalence ratios of $\Phi>1$ are found in the bowl. The injection timing of pilot and main injection has to be adjusted to the swirl ratio as fuel-rich regions move away from the original position of the injection.

\section{Acknowledgements}

This study was performed at the Combustion Research Facility, Sandia National Laboratories in Livermore, CA, USA, and at the Institute of Engineering Thermodynamics (LTT) in Erlangen, Germany. The authors thank Kenneth St Hilaire, Chris Carlen and Gary Hubbard of Sandia National Laboratories for their technical assistance.

\section{Declaration of conflicting interests}

The authors declare that there is no conflict of interest.

\section{Funding}

Support for this research was provided by the US Department of Energy (Office of Vehicle Technologies) and General Motors Corporation (agreement no. FI083070326). Sandia is a multi-program laboratory operated by Sandia Corporation, a Lockheed Martin Company, for the US Department of Energy's National Nuclear Security Administration under contract DE-AC04-94AL85000. This research was also financially supported by the Erlangen Graduate School in Advanced Optical Technologies (SAOT) at the Friedrich-Alexander-Universität Erlangen-Nürnberg, Germany, which is funded by the German National Science Foundation (DFG) within the framework of the Excellence Initiative of the German Federal and State Governments to Promote Science and Research at German Universities.

\section{References}

1. Einecke S, Schulz C and Sick V. Measurement of temperature, fuel concentration and equivalence ratio fields using tracer LIF in IC engine combustion. Appl Phys B 2000; 71: 717-724. 
2. Schulz C and Sick V. Tracer-LIF diagnostics: quantitative measurement of fuel concentration, temperature and fuel/air ratio in practical combustion systems. Prog Energ Combust 2005; 31: 76-121.

3. Löffler M, Beyrau F and Leipertz A. Acetone laserinduced fluorescence behavior for the simultaneous quantification of temperature and residual gas distribution in fired spark-ignition engines. Appl Optics 2009; 49: 37-49.

4. Rothamer DA, Snyder JA, Hanson RK and Steeper RR. Optimization of a tracer-based PLIF diagnostic for simultaneous imaging of EGR and temperature in IC engines. Appl Phys B 2010; 99: 371-384.

5. Luong M, Zhang R, Schulz C and Sick V. Toluene laserinduced fluorescence for in-cylinder temperature imaging in internal combustion engines. Appl Phys B 2008; 91: 669-675.

6. Devillers R, Bruneaux G and Schulz C. Investigation of toluene LIF at high pressure and high temperature in an optical engine. Appl Phys B 2009; 96: 735-739.

7. Williams B, Ewart P, Wang X, Stone R, Ma H, Walmsley $\mathrm{H}$, et al. Quantitative planar laser-induced fluorescence imaging of multi-component fuel/air mixing in a firing gasoline-direct-injection engine: effects of residual exhaust gas on quantitative PLIF. Combust Flame 2010; 157: 1866-1878.

8. Koch P, Löffler M, Wensing M and Leipertz A. Study of the mixture formation processes inside a modern directinjection gasoline engine. Int J Engine Res 2010; 11: 455 471.

9. Trost J, Zigan L and Leipertz A. Quantitative vapor temperature imaging in DISI-sprays at elevated pressures and temperatures using two-line excitation laser-induced fluorescence. P Combust Inst 2013; 34: 3645-3652.

10. Berckmüller M, Tait NP, Lockett RD, Greenhalgh DA, Ishii $\mathrm{K}$, Urata $\mathrm{Y}$, et al. In-cylinder crank angle resolved imaging of fuel concentration in a firing spark-ignitionengine using planar laser-induced fluorescence. $P$ Combust Inst 1994; 25: 151-156.

11. Petersen B, Miles PC and Sahoo D. Equivalence ratio distributions in a light-duty diesel engine operating under partially premixed conditions. SAE Int J Eng 2012; 5: 526-537.

12. Tea G, Bruneaux G, Kashdan JT and Schulz C. Unburned gas temperature measurements in a surrogate diesel jet via two-color toluene-LIF imaging. P Combust Inst 2011; 33: 783-790.

13. Musculus MPB, Lachaux T, Pickett LM and Idicheria A. End-of-injection over-mixing unburned hydrocarbon emissions in low-temperature-combustion diesel engines. SAE technical paper 2007-01-0907, 2007.

14. Hotta Y, Inayoshi M, Nakakita K, Fujiwara K and Sakata I. Achieving lower exhaust emissions and better performance in an HSDI diesel engine with multiple injection. SAE technical paper 2005-01-0928, 2005.

15. Ricaud JC and Lavoisier F. Optimizing the multiple injection settings on an HSDI diesel engine. In: THIESEL 2002, conference on thermo- and fluid dynamic processes in diesel engines, Valencia, 11-13 September 2002, pp.251-275.

16. Badami M, Millo F and D'Amato D. Experimental investigation on soot and $\mathrm{NO}_{\mathrm{x}}$ formation in a DI common rail diesel engine with pilot injection. SAE technical paper 2001-01-0657, 2001.
17. Kastner O, Atzler F, Müller A, Weigand A, Wenzlawski $\mathrm{K}$ and Zellbeck $\mathrm{H}$. Multiple injection strategies and their effect on pollutant emission in passenger car diesel engines. In: THIESEL 2006, conference on thermo- and fluid dynamic processes in diesel engines, Valencia, 12-15 September 2006, pp.61-75.

18. Badami M, Mallamo F, Millo F and Rossi EE. Experimental investigation on the effect of multiple injection strategies on emissions, noise and brake specific fuel consumption of an automotive direct injection common-rail diesel engine. Int J Engine Res 2003; 4: 299-314.

19. Hasse $\mathrm{C}$ and Peters N. Modelling of ignition mechanisms and pollutant formation in direct-injection diesel engines with multiple injections. Int $J$ Engine Res 2005; 6: 231246.

20. Park C, Kook S and Bae C. Effects of multiple injections in a HSDI diesel engine equipped with common rail injection system. SAE technical paper 2004-01-0127, 2004.

21. Carlucci P, Ficarella A and LaForgia D. Effects on combustion and emissions of early and pilot fuel injections in diesel engines. Int J Engine Res 2005; 6: 43-60.

22. Mendez S and Thirouard B. Using multiple injection strategies in diesel combustion: potential to improve emissions, noise and fuel economy trade-off in low CR engines. SAE technical paper 2008-01-1329, 2008.

23. Anaselmi P, Kashdan J, Bression G, Ferrero-Lesur E, Thirouard B and Walter B. Improving emissions, noise and fuel economy trade-off by using multiple injection strategies in diesel low temperature combustion (LTC) mode. SAE technical paper 2010-01-2162, 2010.

24. Vogel T, Wensing M, Leipertz A, Iannuzzi S and Lutz M. Influence of the fuel quantity on the spray formation and ignition under current engine relevant conditions. SAE technical paper 2011-01-1928, 2011.

25. Kastner O, Atzler F, Juvenelle C, Rotondi R and Weigand A. Directly actuated piezo injector for advanced injection strategies towards cleaner diesel engines. In: $7 \mathrm{th}$ international symposium towards clean diesel engines, Aachen, 4-5 June 2009.

26. Carlucci P, Ficarella A and Laforgia D. Effects of pilot injection parameters on combustion for common rail diesel engines. SAE technical paper 2003-01-0700, 2003.

27. Terazawa Y, Nakai E, Kataoka M and Sakono T. The new Mazda four-cylinder diesel engine. MTZ Worldwide 2011; 72: 26-32.

28. Catania A, d'Ambrosio S, Finesso R, Spessa E, Cipolla $\mathrm{G}$ and Vassallo A. Combustion system optimization of a low compression-ratio PCCI diesel engine for light-duty application. SAE technical paper 2009-01-1464, 2009.

29. Kanda T, Kobayashi S, Matsui R and Sono H. Study on euro IV combustion technologies for direct injection diesel engine. SAE technical paper 2004-01-0113, 2004.

30. Kitamura T and Ito T. Mixing-controlled, low temperature diesel combustion with pressure modulated multipleinjection for HSDI diesel engine. SAE technical paper 2010-01-0609, 2010.

31. Ehleskog R, Ochoterena RL and Andersson S. Effects of multiple injections on engine-out emission levels including particulate mass from an HSDI diesel engine. SAE technical paper 2007-01-0910, 2007.

32. Koban W, Koch JD, Hanson RK and Schulz C. Oxygen quenching of toluene fluorescence at elevated temperatures. Appl Phy B 2005; 80: 777-784. 
33. Fuchs R, Krenzer L and Gaube J. Excess properties of binary mixtures composed of a polar component and an alkane. Ber Bunsen Phys Chem 1984; 88: 642-649.

34. Shen $\mathrm{S}$ and Nagata I. Prediction of excess enthalpies of ketone-alkane systems from infinite dilution activity coefficients. Thermochim Acta 1995; 258: 19-31.

35. Le Coz J-F and Baritaud T. Application of laser induced fluorescence for measuring the thickness of evaporating gasoline liquid films. In: Developments in laser techniques and applications to fluid mechanics: proceedings of the 7th international symposium, Lisbon, 11-14 July 1996, pp.115-131. Berlin/Heidelberg: Springer-Verlag.

36. Han B and Steeper R. Examination of iso-octane/ketone mixtures for quantitative LIF measurements in a DISI engine. SAE technical paper 2002-01-0837, 2002.

37. Hentschel W, Schindler K-P and Haahtela O. European diesel research IDEA: experimental results from DI diesel engine investigations. SAE technical paper 941954, 1994.

38. Zhao H and Ladommatos N. Optical diagnostics for incylinder mixture formation measurements in IC engines. Prog Energ Combust 1998; 24: 297-336.

39. Kaiser SA and Long MB. Quantitative planar laserinduced fluorescence of naphthalenes as fuel tracers. $P$ Combust Inst 2005; 30: 1555-1563.

40. Orain M, Baranger P, Rossow B and Grisch F. Fluorescence spectroscopy of naphthalene at high temperatures and pressures: implications for fuel-concentration measurements. Appl Phys B 2011; 102: 163-172.

41. Faust S, Tea G, Dreier T and Schulz C. Temperature, pressure, and bath gas composition dependence of fluorescence spectra and fluorescence lifetimes of toluene and naphthalene. Appl Phys B 2013; 110: 81-93.
42. Trost J, Zigan L, Leipertz A, Sahoo D and Miles PC. Characterization of four different potential laser-induced fluorescence tracers for diesel engine application. Appl Optics 2013; 52: 8001-8007.

43. Leininger J-P, Lorant F, Minot C and Behar F. Mechanisms of 1-methylnaphthalene pyrolysis in a batch reactor. Energ Fuel 2006; 20: 2518-2530.

44. FLUIDAT $^{\circledR}$ on the Net V 1.39/6.18 - mass flow and physical property calculator, 2013, www.fluidat.com

45. Davy M, Williams P, Han D and Steeper R. Evaporation characteristics of the 3-pentanone-isooctane binary system. Exp Fluids 2003; 35: 92-99.

46. Daubert TE and Danner RP. Physical and thermodynamic properties of pure chemicals: data compilation. Washington, DC: Taylor \& Francis, 1989.

47. Weast RC. CRC handbook of chemistry and physics. 70th ed.Boca Raton, FL: CRC Press, 1989.

48. Colban WF, Kim D, Miles PC, Oh S, Opat R, Krieger R, et al. A detailed comparison of emissions and combustion performance between optical and metal single-cylinder diesel engines at low temperature combustion conditions. SAE Int J Fuels Lubr 2008; 1: 505-519.

49. Staples LR, Reitz RD and Hergart C. An experimental investigation into diesel engine size-scaling parameters. SAE Int J Eng 2009; 2: 1068-1084.

50. Miles PC, RempelEwert B and Reitz RD. Squish-swirl and injection-swirl interaction in direct injection diesel engines. In: Proceedings of ICE 2003-6th international conference on engines for automobile, Capri-Naples, 14 19 September 2003. 